\title{
Analysis and Countermeasures on Accounting Informatization Quality Problem
}

\author{
Genxia LIU
}

Accounting department, Henan institute of engineering, China

\begin{abstract}
With the wide application of information technology and the establishment of a resource-saving society, accounting informatization has made considerable progress in depth and breadth.But there are still many problems in the work of accounting informatization, such as the hardware structure is not reasonable, selection of software is not scientific, basic work is not standard, poor quality of accounting data, Security risk control is not perfect, and Low system efficiency. By analyzing the causes of these problems, and puts forward measures to improve the quality of accounting information.
\end{abstract}

KEYWORD: Accounting Informatization; Quality Problem; Reason Analysis; Improving Measures

Accounting information, from a macro point of view, is an important part of national informatization strategy in our country, from the microscopic point of view, is a more cost, manpower, material resources consumption, long life cycle of systems engineering [1]. January 6, 2014 the formal implementation of the "Enterprise Accounting Information Standards" (hereinafter referred to as "Code") for enterprise work play a regulatory, guidance and promotion role on accounting information. However, there are also unreasonable hardware architecture, software selection is unscientific, foundation work is not standardized, accounting data quality is not high, security and risk system is not sound, and low system efficiency, enterprises and institutions. This can lead to accounting information can't meet the demand of enterprise expectations, restrict the depth and breadth of accounting informatization application. Therefore it is necessary to thoroughly analyze the reasons of accounting information quality problem, to provide a solution to promote the development of accounting information.

\section{THE PROBLEMS IN ACCOUNTING INFORMATION QUALITY}

Accounting information quality problems have different performance in different stages. During construction period, there are the problems, such as hardware and software selection mismatch development of enterprises, and nonstandard foundation work, etc. And run-time problems mainly for generation of accounting information quality is not high, the system stability, the response and recovery of failure to be improved and so on.

\subsection{The hardware architecture is unreasonable}

Accounting information systems hardware architecture configurations need to consider the characteristics and efficiency of the enterprise management. Hardware platform selection unscientific, on the one hand will affect the future of the system scalability, on the other hand will also affect the accounting data collection, transfer and application, lead to poor decision-making efficiency.

\subsection{Software Selection unscientific}

Accounting software is the core of the accounting information system, accounting information in the process of selecting appropriate software is directly related to enterprise demand satisfaction. Too much consideration on technology or price or function of the software, will lead people to ignore some problems of accounting information itself to be solved. The software selection, which does not match enterprise management requirements and internal and external business environment, not only can cause waste of much money, but also can not improve efficiency, reduce costs and increase benefit. 


\subsection{The management infrastructure is not standardized}

Specific management foundation is the guarantee for the implementation of information technology. The implementation of informatization requires enterprise management systematic, process normalization and quota standardization. Non-standard foundation work often happens in business process, it will result in the initial set of accounting information (1) the reality and reliability of input data cannot be guaranteed; (2) can't make reasonable accounting policy choice according to the actual circumstance of enterprise; (3) cannot prevent the occurrence of fraud from the system; (4) cannot output useful accounting information.

\subsection{The business process is not transparent}

Business process is through the integration of a set of operations, use the input of all kinds of necessary resources, by value-added processing, output the products or service which are needed, recognized and satisfied with by customers. Only when the process can be visible or transparent to improve the process or monitor, which can provide customers with innovative and value-added products and services. Accounting information itself is a shock on the original accounting business process. In manual mode, accounting personnel staffing accounting documents according to the original documents, which implies a conversion process of accounting data; the audited for posting vouchers, also implies transcribed operations accounting data. This opaque business processes is likely to cause distortion of accounting information, to reduce the usefulness of the information.

\subsection{The control system is not perfect}

The normal operation of accounting information depends not only on the software in the curing process control to achieve the input, processing and output, but also relies heavily on the operating environment of control. Whether to establish the internal control system and effective operation, which will affect the safe operation and the efficiency of the accounting information system.

\subsection{Accounting data quality is not high}

When it comes to the quality of the accounting data, usually people focused on the authenticity, reliability and clarity. People care more about business process in the process of accounting informatization, "where it comes from, where to go, who will handle", think that accounting data is just produced in the process of information processing "by-products", can be copied and update, and do not consume and is easily destroyed, will change with the changes in the environment, has the instability. If you do not have to implement a unified accounting information plan, each independent subsystems will use different business rules and data model, lead to the granularity, size, and name business data and accounting data are not unified expression, result in some quality problems, such as metadata is not accurate, consistent, repeatable and ambiguity [2].

\section{THE CAUSES OF ACCOUNTING INFORMATION QUALITY PROBLEMS}

\subsection{The lack of accounting information technology strategic planning}

Accounting Information Technology Strategic Planning is a strategic business plan for the establishment and development of accounting information systems made, from the corporate aims, objectives and strategies of view, build enterprise information architecture, unified plan, manage and apply accounting and finance, internal and external information resource, use information to aid decisionmaking, and to help organizations achieve strategic objectives. Accounting informatization planning, can make the information construction is consistent with the organization's overall strategy planning, can reasonably allocate resources, determine the priority order in the accounting information system construction, to avoid conflicts, duplication of development, repeated shortcomings organize data. Lack of development strategy planning, can lead to the development of accounting information from the enterprise strategic goals, unable to improve the efficiency of the organization and management, cause the waste of human, financial and other resources, about $80 \%$ of accounting informatization implementation not achieve expected target companies because they did not develop accounting information development plan.

\subsection{There is no clear definition of enterprise information needs}

Clear enterprise management information needs can help enterprises to identify the overall architecture of the accounting information system and information needs about current and future, boundaries of the subsystems of the accounting information system function, as well as the priority order of development. During accounting information construction, if you can't clear enterprise information demand, will don't clear to these questions, such as "build what kind of system", "system should have what kind of function", "how to implement these functions", lead to hardware architecture and software selection mismatch enterprise management requirements, unable to meet 
the needs of enterprise development and management of information, but also to improve the efficiency and benefit of enterprise.

\subsection{The basic work is inadequate preparation}

"Forewarned is forearmed" means no matter what you do, there is prepared in advance, you can get success, otherwise, you will fail. The truth contained in this statement applies equally to the work of accounting information, the inadequate preparation of basic work can lead to accounting information not work properly, thus influence the effect of accounting informatization. Unadjusted or adjusted organizational structure is not in place, will reduce the enthusiasm of the accounting staff work, restricting the efficiency and correctness of accounting information processing, transmitting, and using. Business process optimization is not in place, will inevitably lead to the accounting business process "in its form," only to replace manual accounting with computational tools, can't really improve the usefulness of accounting information and auxiliary decision-making function. Management system is imperfect, it will lead to the spread of error, and bring a greater risk than manual way. The underlying data is not standardized, information can lead to erroneous repetition and amplification, the accounting information distortion may eventually lead to errors in business management and decision-making.

\subsection{Leadership attention, conceptual change and the quality of staff needs to be improved}

Human factors is crucial to accounting information work, whether it is the leader's emphasis on accounting information technology projects, or ideas and the quality of accounting personnel affect accounting information construction and operation. Leaders attach importance to the work of accounting information, layers of responsibility and pressure will pass, accounting information will be well protected, and the quality of work will be greatly improved. Accounting information is bound to change the flow to collect, transfer and process accounting data, and the use of accounting information, this is a challenge for accounting and related personnel, If accounting and related personnel cannot update knowledge and ideas, can't meet the impact on the accounting information technology development, they will eventually be eliminated.

\section{THE MEASURES TO IMPROVE THE QUALITY OF ENTERPRISE ACCOUNTING INFORMATION}

To improve the quality of enterprise accounting information, combined with practical experience and analysis of the above, the following control measures are put forward.

\subsection{In-depth investigation and good accounting information technology planning}

Accounting information is a systematic project, By evaluating the enterprise existing information system, analyzing enterprise information demand and the resources, to determine the accounting informatization strategic overall architecture, resource allocation mechanism and priority of system development and implementation, and to ensure the integration and coordination of system. Good accounting information technology planning the information resources from enterprise internal and external can be unified planning, use information to control enterprise behavior and to aid decisionmaking, so as to help achieve enterprise strategic objectives.

\subsection{The optimization of business processes}

Optimize the business process is that the enterprise breaks the traditional division of labor function model in the information process, use flow guidance to process business, can improve the speed and quality of business processing, reduce the information acquisition cost. Business process optimization, first of all, is to comprehensively analyze the functionality and efficiency of the original process. Secondly, considering the cost-effectiveness, technology, risk factors, put forward such as process improvement scheme, cancel the invalid link, merge redundant steps, as far as possible automatically treat business process, makes the original process more transparent and to facilitate information integration. Finally, adjust the organizational structure, job division, communication channels and business norms, in order to ensure process improvements to achieve the desired objectives.

\subsection{The establishment of a sound and effective control system}

Security is the premise and foundation of accounting informatization operation, not only to ensure the safety of software and hardware, data, and files, but also to ensure the safety of operation and operating environment. Sound and effective internal control system and management system (including general 
control system, application control) can play a role in the prevention of risk.

General control related to the operation environment of information mainly includes (1) organizational control system; (2) operation control system; (3) the safety control system on hardware and software; (4) data security control system; (5) control system of development and maintenance.

Application control related to the specific process mainly includes (1) the input control; (2) processing control; (3) the output control.

\subsection{The necessary management consulting}

Implementation of major accounting information system is not only a long period, and it takes a lot of manpower, material and financial resources, if the implementation fails, waste time and money, also may cause business risk and financial risk. So in the preparation of the accounting information construction can use external-brain, buy expert service, consult professional implement company, professional management consultancy diagnose for company's problems, combined with business needs, put forward to appropriate solutions or suggestions to implementation of accounting information, help enterprises to improve existing problems, optimize business processes, improve management systems, perfect management system and basic data, which greatly increases the probability of successful implementation of accounting informatization. At the same time, experts in management consulting and implementation of professional services can train enterprise employees, and realize the migration of knowledge.

\section{CONCLUSION}

Along with our country building a conservationminded society, accounting information is an inevitable trend, to plan accounting information in advance, fully mobilize and train staff, actively change ideas, improve business processes, organize basic data and policy, perfect the internal control system, will help to improve the quality of accounting information.

\section{REFERENCES}

[1] Wanmin, Ma.2001.The index system of evaluation of the quality of accounting information system. Research on auditing and economic (9): 46-47

[2] Minru, Zhu \& Qingfeng,Li. 2005. Data quality management and enterprise informatization construction. The computer age (6): 31-32. 